\title{
EXPERIMENTAL TESTS FOR THE CHARACTERIZATION OF SISAL FIBER REINFORCED CEMENTITIOUS MATRIX FOR STRENGTHENING MASONRY STRUCTURES
}

Claudia Brito de Carvalho Bello ${ }^{1 *}$, Ingrid Boem², Antonella Cecchi ${ }^{3}$, Natalino Gattesco ${ }^{4}$, Daniel V.

Oliveira ${ }^{5}$

* Corresponding author

${ }^{1}$ e-mail: decarvalho@iuav.it - tel.: +390412571297 - fax: +390412571282

2e-mail: ingrid.boem@dia.units.it

${ }^{3}$ e-mail: cecchi@iuav.it

${ }^{4}$ e-mail: gattesco@units.it

${ }^{5}$ e-mail: $\underline{\text { danvco@civil.uminho.pt }}$

${ }^{1,3}$ Department of Architecture Construction Conservation (DACC)

University IUAV of Venice

Dorsoduro 2206, 30123 Venezia, Italy

${ }^{2,4}$ Department of Engineering and Architecture

University of Trieste

Piazzale Europa 1, 34127 Trieste, Italy

${ }^{5}$ ISISE, Institute of Science and Innovation for Bio-Sustainability (IB-S), Department of Civil Engineering, University of Minho, Guimarães, Portugal

\begin{abstract}
The experimental characterization of a Natural Fiber Reinforced Cementitious Matrix (NFRCM), made of sisal fibers yarns impregnated with a water-based resin and embedded in an inorganic matrix based on natural lime is presented in thise paper. The Sisal-NFRCM performances are investigated through tensile and single-lap shear tests, adopting the dispositions of the Round Robin Tests developed for the FRCM characterization by the RILEM Technical Committee 250-CSM. The tensile stress-strain curve evidenced the tension stiffening effect of the mortar between cracks, which tended progressively to reduce. In shear tests, the failure and the progressive slippage of the sisal yarns was observed.
\end{abstract}

\section{Keywords}

NFRCM, TRM, FRCM, masonry, natural fiber, sisal fiber, tensile test, shear test, experimental test 


\section{Introduction}

The Fiber Reinforced Cementitious Matrix (FRCM), also known in the literature as Textile Reinforced Mortar (TRM), represents an innovative structural method for masonry strengthening. The first use of FRCM was in the late 1990s in Europe, on few construction applications. FRCM systems are constituted by fibers - arranged as open fabric meshes - embedded in an inorganic matrix. The fibers carry tensile stresses and the matrix ensures the load transfer among the fibers and improve long-term durability. Moreover, the fiber may also be coated to improve the adhesion with the matrix. The fiber materials commonly used are carbon, glass, steel, aramid, basalt, polyparaphenylenebenzobisoxazole (PBO); they are from non-renewable sources or synthetic materials and FRCM systems with vegetal fibers are not in commerce yet.

At present time, only the US AC434 [1] and ACl 549.4R-13 [2] codes are available as a guide to the FRCM design and experimental tests for the application on masonry and reinforced concrete structures. In Europe, the RILEM TC 250-CSM (Composites for Sustainable strengthening of Masonry) organized a Round Robin Test (RRT), involving 19 research institutions from 6 European countries (France, Germany, Greece, Italy, Poland, Portugal and Slovenia), and 11 industrial partners (10 Italians and 1 Greek). The overall investigation included direct tensile and bond tests [3]-[4]. The main experimental results of the Round Robin are reported in detail in five papers, organized by textile material: basalt [5], carbon [6], glass [7], aramid and PBO [8] and steel [9].

Despite the big effort on research in the last years, the knowledge on FRCM mechanical behavior is still incomplete: further experimental data are needed to better understand how the influence of the textile layout, the fibers coating and the matrix composition affects the mechanical behavior of the FRCM composite. Moreover, long-term durability in aggressive environments needs to be carefully investigated.

Also, further FRCM experimental and numerical investigations are necessary to gain a sustainable reinforcement technique, using composites consisted by renewable resources, as meshes or textiles made of natural fibers. In fact, sustainability is becoming a very current, crucial issue in the building sector due to the growing attention on the environmental impact of building materials and processes.

Natural fiber-reinforced composites are emerging very rapidly thanks to developments in research aimed to improve the durability limitations, as treatments and coating systems [10] or bio-based resins production for bio-composite systems with natural fibers [11]-[12]. Natural fibers can actually replace metal or ceramic-based materials in several applications for the automotive, aerospace, electronics and construction industries [13]-[15]. In particular, vegetal fibers textiles composites show good mechanical properties, implying reduced thickness and low weight [16]-[17]. Considering plant fibers, the mostly used in the civil engineering field are bast fibers (flax, hemp, jute and ramie) and leaf fibers (abaca, sisal, banana, pineapple).

This work is part of a larger research program that investigates the strengthening of masonry through FRCM systems using sustainable materials and deals with the possibility of replacing the most commonly used inorganic or synthetic fibers with organic natural ones and, in particular, plant fibers. The paper focuses on sisal fibers: some researchers already investigated their properties and their use for a Natural FRCM (NFRCM) strengthening technique for masonry structures [18]-[21]. In particular, Olivito et al. [21] performed characterization tests on NFRCM made of sisal and flax fabrics, demonstrating for such composites an appreciable ductile behaviour and moderate tensile strengths.

To investigate the mechanical performances of sisal-NFRCM, experimental tests were carried out following the Round Robin Test methodology formulated by the RILEM Technical Committee TC 250-CSM. 
As required by the RILEM protocol, the tests were performed in different laboratories: at the University IUAV of Venice and at the University of Trieste. The same samples characteristics and test set-ups were adopted in both laboratories. The sisal-NFRCM samples, produced by the composite factory Fibrenet SpA (Pavia di Udine, Italy), were made with sisal fibers yarns impregnated with a water-based adhesive promoter and embedded into a natural lime mortar. The characterization of the NFRCM constituents (sisal yarns and mortar) was achieved. Then, both laboratories performed tensile tests on sisal-NFRCM coupons, to characterize its tensile behavior, and single-lap shear tests on the sisal-NFRCM reinforcement applied to a brickwork substrate, to set the bond performance.

The tests permitted to obtain important and original information on the behavior of sisal-NFRCM, useful for design purposes and also for numerical simulations. Considering, for example, the application of the sisal-NFRCM on a masonry wall to improve its out-of-plane bending performance, it is necessary to know the actual tensile behavior of the reinforcement acting on the tensed wall face; moreover, to provide an effective contribution, the reinforcement has to be properly anchored.

The tests permitted also to derive some considerations on the application of the RILEM RRT testing protocol, developed for common FRCM, on this specific type of reinforcement.

\section{Characterization of the sisal-FRCM constituents}

A full characterization of the composite constituents (yarns and mortar) is described in the following sections.

\subsection{Natural and impregnated Sisal yarns characterization}

Sisal yarns from Tanzania were used (Fig. 1a). The yarn is composed by twisted filaments of long fibers.

The specimens were obtained by cutting $500 \mathrm{~mm}$ length samples from the sisal roll (Fig. 1b). The samples were conditioned 15 days into an alkaline solution with calcium hydroxides and pH 12.5 to stabilize the cellular structure and the tensile response [22].

The geometric and mechanical characterization of both non-impregnated and impregnated sisal yarns was accomplished. An Interpenetrating Polymer Network (IPN), based on a two-component, water-based adhesive with low viscosity, was used for the impregnation. This IPN is suitable for the preparation of concrete, masonry or wood surfaces and the impregnation of fiberglass or carbon fiber reinforcements; it is durable in lime or cement mortars alkaline environment and fire proof.

The fiber area, $A\left[\mathrm{~mm}^{2}\right]$, was evaluated by dividing the yarn linear density, $T_{x}$, expressed in tex $[\mathrm{g} / \mathrm{km}]$, by the yarn density, $\rho\left[\mathrm{g} / \mathrm{cm}^{3}\right] \div$

$$
A=\frac{T_{x}}{\rho} \times 10^{-3}
$$

The calculation of $T_{x}$ was obtained in accordance with EN ISO 1889:2009 [23]:

$$
T_{x}=\frac{P \cdot 1000}{L},
$$

Where $P$ is the weight of the sample $[\mathrm{g}]$ and $L$ stands for the length [m]. The average values of $T_{x}$ and $A$ obtained from 5 samples are 3130 tex (CoV 1.5\%) and $2.09 \mathrm{~mm}^{2}$ (CoV 3.4\%), respectively. The considered yarn density $\rho$ was $1.5 \mathrm{~g} / \mathrm{cm}^{3}$, according to Pickering et al. [24]. The equivalent area of impregnated yarns, $A_{\text {eq }}$, was estimated from the measurement of the specimen volume $V$, in accordance with CNR-DT 200 R1/2013 standard [25]:

$$
A_{\text {eq }}=\frac{V}{L} \text {. }
$$


The average value of $A_{\text {eq, }}$ obtained from 5 samples, is $5.4 \mathrm{~mm}^{2}$ (CoV $13.1 \%$ ).

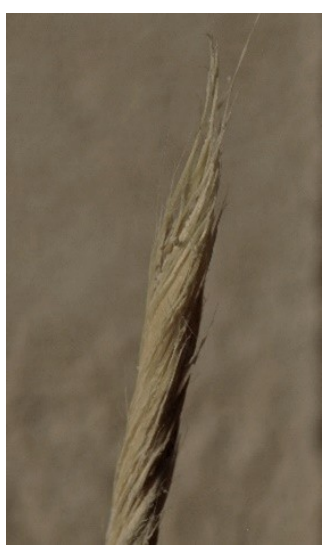

(a)

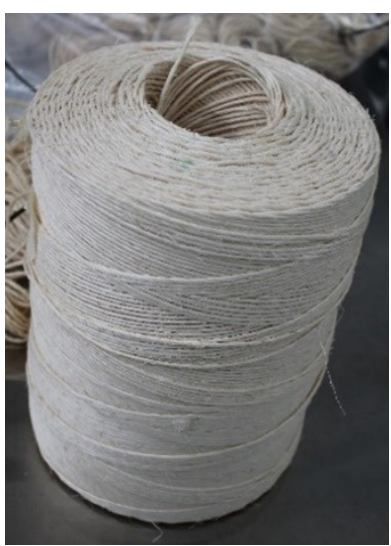

(b)

Fig. 1 Detail of a sisal yarn (a) and yarn roll (b)

Direct tensile tests on both natural and impregnated fibers were carried out on single yarns at at current laboratory conditions, using a Galdabini Sun 20 machine (20 KN capacity), conducted at displacement control with a speed rate of $10 \mathrm{~mm} / \mathrm{min}$.

The stress-strain curves of three natural yarns samples are plotted in Fig. 2, in green color. They show an initial linear elastic branch and a second non-linear phase associated to the progressive rupture of the fibers, due to an uneven stress distribution. The average maximum tensile load is 437 $\mathrm{N}$ (CoV 9.5\%) and the calculated tensile strength results equal to 209.1 MPa. The results are in good agreement to those obtained through the same tests performed on five samples by De Carvalho Bello and Cecchi [22].

The blue stress-strain curves in Fig. 2 refer to four impregnated yarns samples and evidence an elastic brittle behavior, with an average tensile maximum load of $500 \mathrm{~N}$ (CoV 11.4\%) and ultimate strain 3.04\% (CoV 4.9\%). The average tensile strength resulted of $239.7 \mathrm{MPa}$, referring to the crosssection of the non-impregnated yarn $(A)$, and of $92.6 \mathrm{MPa}$, using the area of the impregnated one $\left(A_{\text {eq }}\right)$. The yarn equivalent Young modulus, evaluated as secant of the stress-strain curve at $60 \%$ of the peak stress, resulted in $\mathrm{E}=7853 \mathrm{MPa}$ (CoV 6.8\%); the mean axial stiffness is thus $\mathrm{EA}=16413 \mathrm{~N}$. When compared to the results of non-impregnated yarns, the impregnated ones presented a higher resistance (about $+14 \%$ ): actually, the impregnation allowed a more uniform distribution of the stresses among the fibers, avoiding their premature gradual failure.

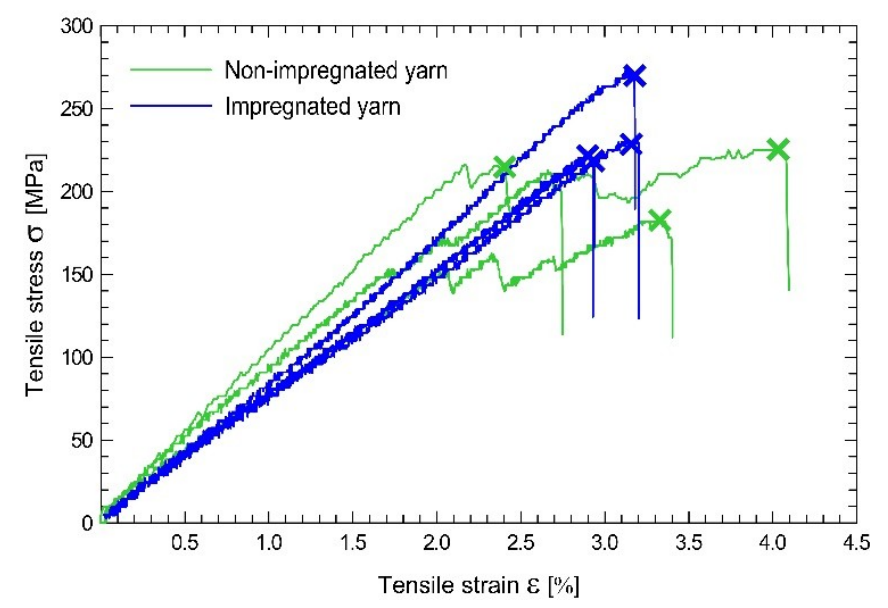


Fig. 2 Direct tensile tests on sisal yarns: non-impregnated (green) and impregnated (blue) yarns stress-strain curves (stresses are calculated considering a non-impregnated yarn cross-section of $2.09 \mathrm{~mm}^{2}$ )

\subsection{Mortar characterization}

The inorganic matrix considered for the NFRCM composite is a pre-mixed mortar in which the main binder is the Natural Hydraulic Lime (NHL). The NHL-based mortar is suitable for building restoration, in accordance to EN 1998-1:2004 standard [26]. The mortar mechanical characterization was set through experimental tests performed on six prismatic samples $\left(40 \times 40 \times 160 \mathrm{~mm}^{3}\right)$, in accordance to EN 196-1:2016 standard [27] (Fig. 3 ). Results showed an average flexural strength of $3.5 \mathrm{MPa}(\mathrm{CoV} 3.5 \%)$ and an average compressive strength of $13 \mathrm{MPa}$ (CoV 1.8\%). The average mass density was $1624 \mathrm{~kg} / \mathrm{m}^{3}$.

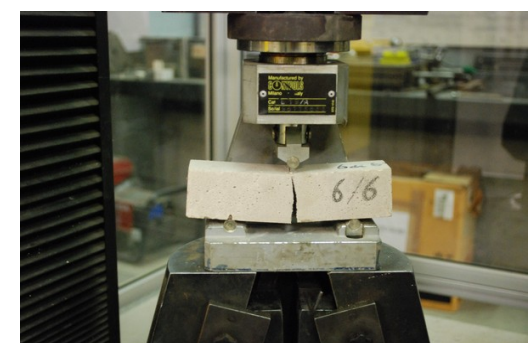

(a)

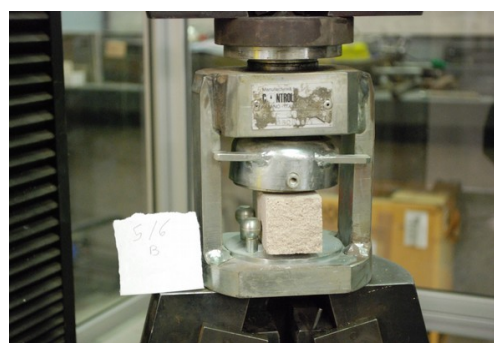

(b)

Fig. 3 Experimental tests on mortar prismatic specimens, to determinate the flexural (a) and compressive (b) strengths

\section{Tensile tests on Sisal-NFRCM coupons}

The tensile tests on the Sisal-FRCM coupons aim to study the tensile response of the composite and the effect of the intact mortar between cracks (tension stiffening effect).

\subsection{Specimens}

The specimens were prismatic samples of mortar with a layer of sisal yarns embedded. The prisms dimensions were $75 \mathrm{~mm}$ width, $500 \mathrm{~mm}$ length and $10 \mathrm{~mm}$ thick (Fig. 4). The reinforcement is constituted by five impregnated yarns disposed in the longitudinal direction and placed in the middle of the specimen thickness.

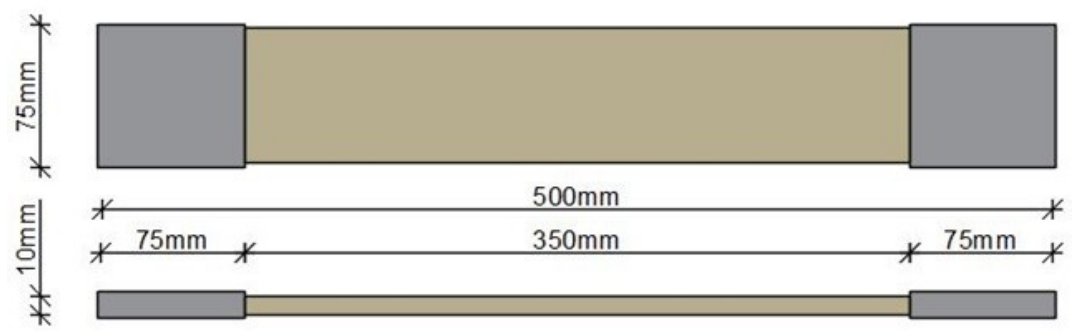

(a)

(b)

Fig. 4 Sisal-FRCM specimen geometry: front (a) and lateral (b) views

The specimens were produced with particular attention to the alignment of the yarns, to avoid parasitic stresses during test execution. Fig. 5 illustrates the specimens manufacturing process, with the first half thickness layer of mortar, about $5 \mathrm{~mm}$ thick (a), the sisal yarns disposed in the longitudinal direction (b), the manual impregnation with the adhesion promoter (c) and the last half 
of mortar, about $5 \mathrm{~mm}$ thick (d). It is worth to note that; in actual applications on masonry walls, this type of reinforcement should reasonably be composed of bidirectional yarns (arranged as a textile or a mesh). Thus, transversal yarns can somehow improve the anchorage performances of the longitudinal ones to the matrix, depending on the consistency of the intersection between yarns (e.g. simple weft-warp weaving or making knots). However, since this was a preliminary characterization study, the contribution of the transversal yarns was prudentially neglected.

The specimens were cured for 60 days, at $23 \pm 2^{\circ} \mathrm{C}$ temperature and 50-60\% relative humidity conditions. Specific tabs $\left(75 \times 75 \mathrm{~mm}^{2}\right)$ were applied at the samples extremities. According to RILEM indications, these tabs would avoid cracking and crushing in correspondence to the grip areas during the experimental test [3]. Actually, two overlapped CFRP (Carbon Fiber Reinforced Polymer) strips were applied by the impregnation of the carbon-based fabric with epoxy resin (Fig. 6a).
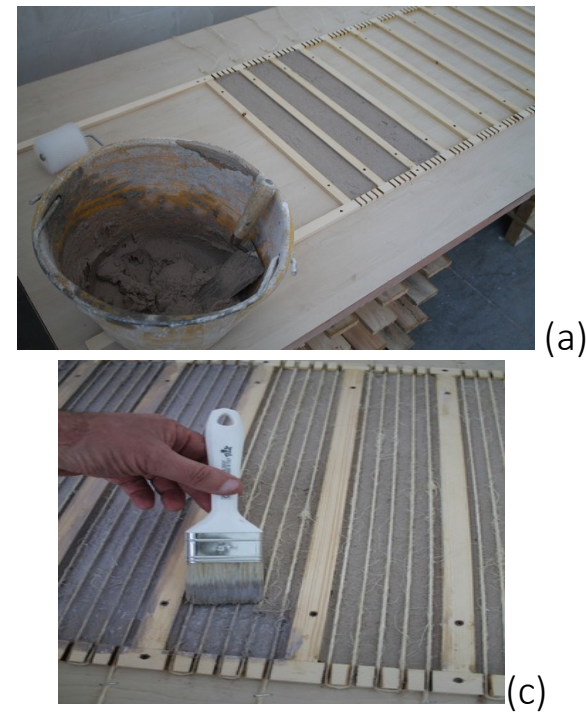

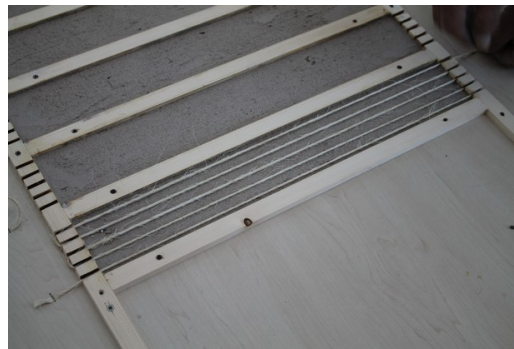

(b)

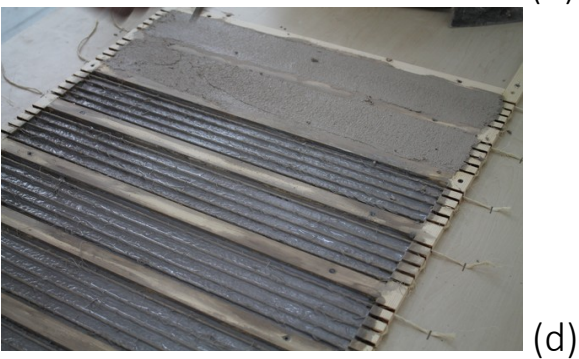

(d)

Fig. 5 Sisal-NFRCM samples manufacturing for tensile tests: application of the first layer of mortar (a), positioning of the sisal yarns (b), impregnation of the yarns with the adhesive promoter (c) and application of the second layer of mortar (d)

\subsection{Test set-up and procedure}

At the University IUAV of Venice laboratory, the tests were carried out with a universal Dartec machine, controlled by a Zwick-Roll system, using the software Testexpert II, under displacement control (Fig. 6b). Two digital transducers were positioned along the specimens, one on each side, with a base length, $l_{d}$ of $250 \mathrm{~mm}$, for monitoring the elongation during the load application.

An illustration of the test setup adopted in the University of Trieste laboratory is reported in Fig. 6c [28]. The apparatus consisted of a metallic portal connected to a stiff reinforced concrete pavement and an electromechanical actuator, fixed at the pavement and placed between the two portal posts. The actuator (Costamasnaga K150, $300 \mathrm{kN}$ capacity, $300 \mathrm{~mm}$ stroke) was installed at the top of the metallic base and was controlled by an electrical engine. On the top of the actuator, two coupled steel plates were installed so to create the lower clamping head for the samples. A loading cell (AEP Transducers, Type TC4 AMP 50kN) was mounted on the portal beam and, below, the upper holding of the sample (coupled steel plates) was positioned. The interposition of knuckle joints permitted to overcome for possible parasitic bending forces that may arise in the samples. The test apparatus was dimensioned so to limit as close as possible the elastic deformation related to the metallic elements and connections (apparatus deformation $<0.005 \mathrm{~mm}$ for a tensile load of $1 \mathrm{kN}$ ). Two potentiometer transducers (base lengths $I_{d}=250 \mathrm{~mm}$ and $325 \mathrm{~mm}$ ) were placed along the specimens for monitoring the sample elongation during the loading procedure. 
A schematization of the test setup is reported in Fig. $6 \mathrm{~d}$-e. In both laboratories, the clamping of the specimens at both ends was realized by friction, applying a compressive load of about $20 \mathrm{kN}$ (compressive stress $\approx 3.6 \mathrm{MPa}$ ). The load rate was about $0.3 \mathrm{~mm} / \mathrm{min}$, in the un-cracked phase (in order to provide recording the first phase of the test) and $0.5 \mathrm{~mm} / \mathrm{min}$ after the cracking phase and with an acquisition frequency equal to $5 \mathrm{~Hz}$.

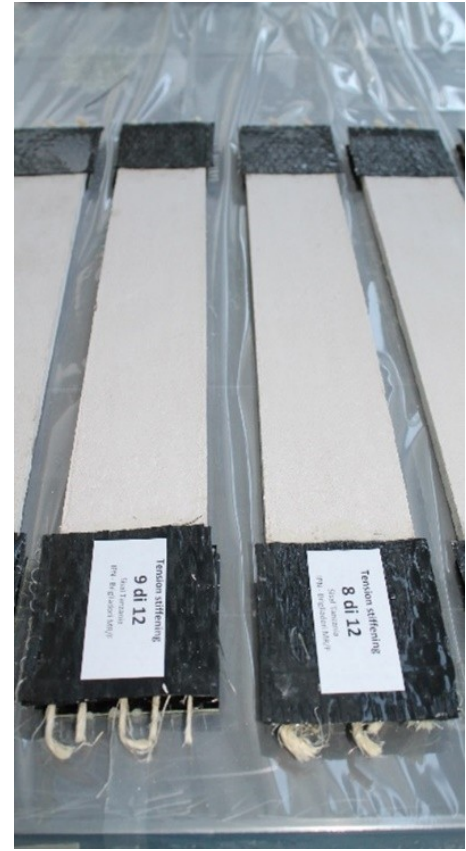

(a)

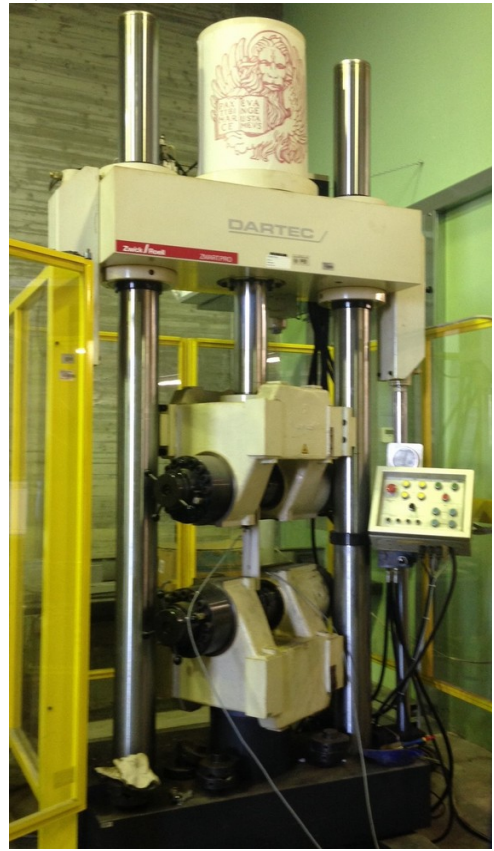

(b)

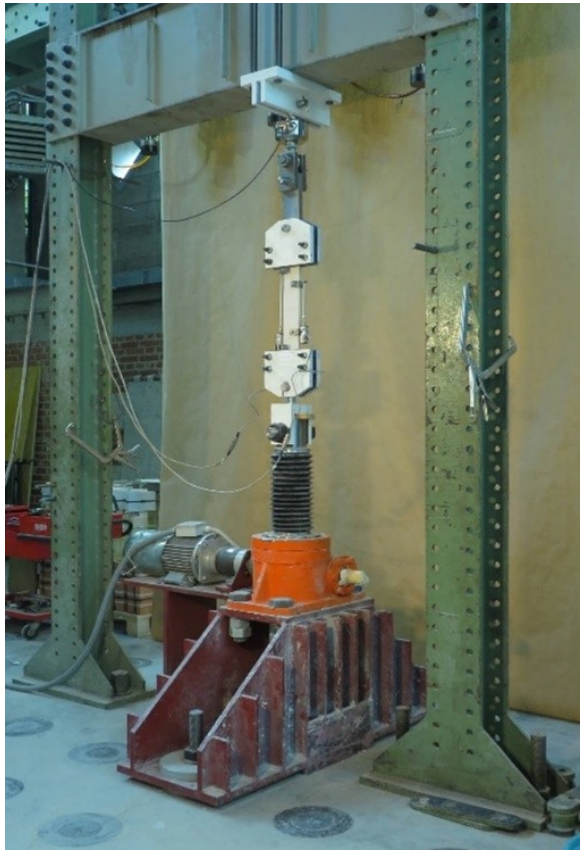

(c)

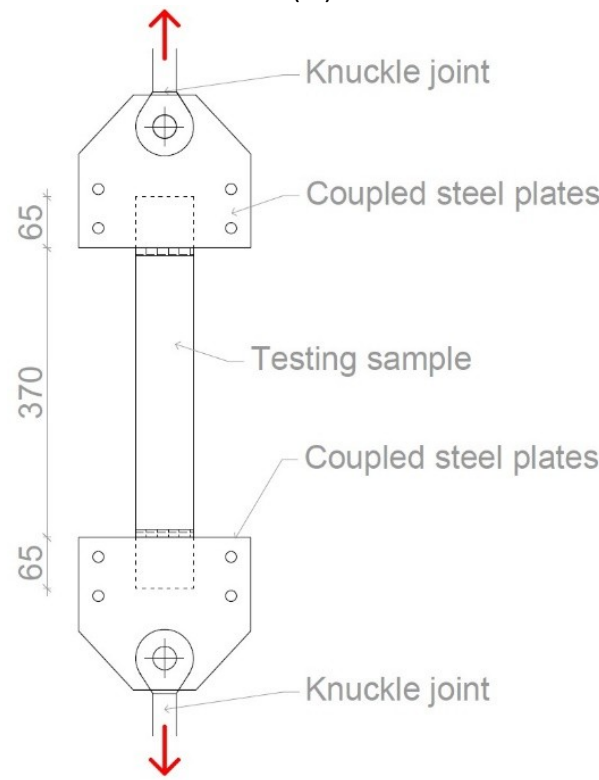

(d)

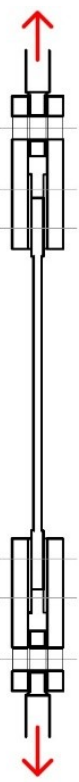

(e)

Fig. 6 Tensile tests on sisal-NFRCM samples: some specimens before testing (a) and test set-up at University IUAV of Venice (b) University of Trieste (c); frontal view (d) and lateral section (e) of the test apparatus

\subsection{Results and discussions}

The results of the samples tested in Trieste (named TT1 up to TT6) and in Venice (named TT7 up to TT12) are illustrated in Fig. 7. The corresponding stress-strain curves are reported in Fig. 8. It is observed that the curves obtained in each laboratory are, in general, coherent among them and 
that the Trieste and Venice results are comparable. Actually, sample TT8 attained too lower values in terms of both strength and strain, as a consequence of a premature damage, being thus considered as an invalid test.

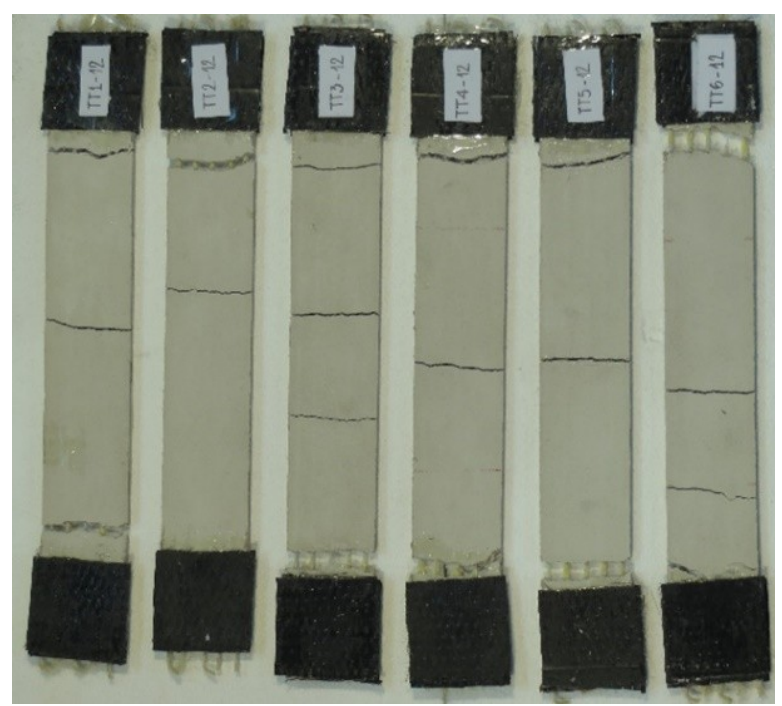

(a)

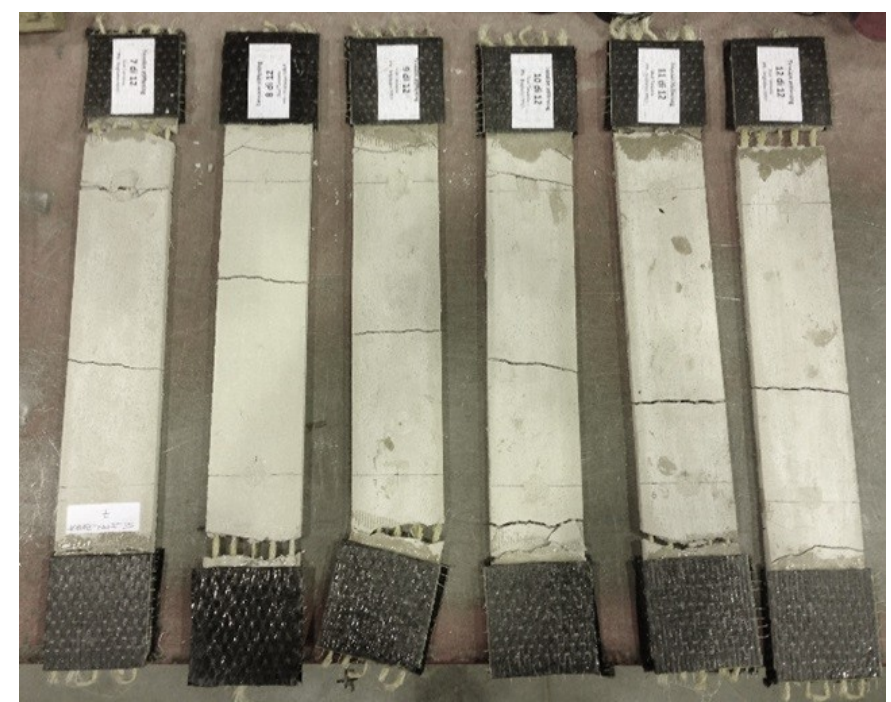

(b)

Fig. 7 Cracked samples after the tensile tests: samples TT1-TT6 tested in Trieste (a) and TT7-Tा12 tested in Venice (b)

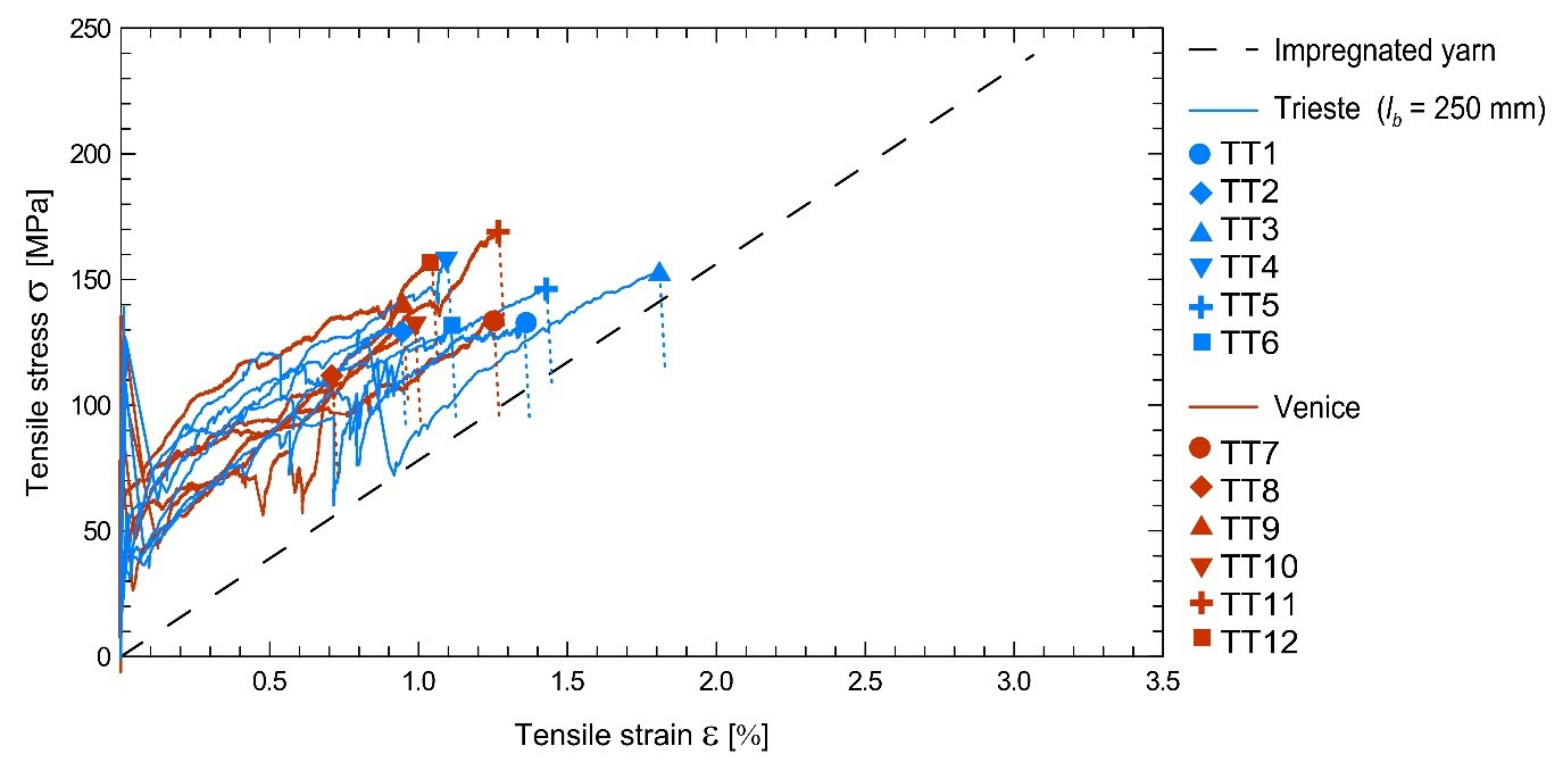

Fig. 8 Tensile behavior of Sisal-FRCM: stress-strain curves obtained by the Trieste laboratory (using transducers with a $250 \mathrm{~mm}$ base length) and by the Venice laboratory.

The main results are summarized in Tab. 1 , reporting $\div$ the cracking load $\left(F_{c r}\right)$, the peak load $\left(F_{\text {max }}\right)$, the tensile stress in correspondence with the peak load $\left(\sigma_{\max }\right)$ related to the fibers cross section (2.09 $\mathrm{mm}^{2} \times 5$ yarns $\left.=10.45 \mathrm{~mm}^{2}\right)$, the transducers base lengths $\left(I_{d 1}, I_{d 2}\right)$, the measured displacements in correspondence with the peak load $\left(D_{\max 1}, D_{\max 2}\right)$, the mean tensile strains values $\left(\varepsilon_{\max 1}=D_{\max 1} / l_{d 1}, \varepsilon_{\max 2}=D_{\max 2} / I_{d 2}\right)$. Moreover, the collapse mode of samples is indicated according to the classification adopted by De Santis et al. [9] (Fig. 9). 
The typical FRCM behavior under tension generally presents a stress-strain curve with a trilinear behavior characterized by: (i) a first phase that represents the uncracked stage or elastic branch, where the material stiffness depends on the mortar Young's modulus; (ii) a second phase; that corresponds to the formation and propagation of multiple transversal, parallel cracks in the mortar; (iii) a third, post-cracking phase, with progressive crack widening until the tensile fibers rupture. In this phase, the stress-strain curve is almost parallel to the tensile curve of the yarns alone. The horizontal gap between the third branch and the stand-alone yarns curve is due to the tension stiffening effect of the mortar between the cracks. The composite behavior depends on the constituent materials properties and interactions [29].

Tab. 1 Tensile tests results on sisal-NFRCM samples

\begin{tabular}{|c|c|c|c|c|c|c|c|c|c|c|}
\hline $\begin{array}{l}\text { Sam } \\
\text { ple }\end{array}$ & $\begin{array}{l}\mathrm{F}_{\mathrm{cr}} \\
{[\mathrm{N}]}\end{array}$ & $\begin{array}{l}\mathrm{F}_{\max } \\
{[\mathrm{N}]}\end{array}$ & $\begin{array}{c}\sigma_{\max } \\
{[\mathrm{MPa}]}\end{array}$ & $\begin{array}{c}\mathrm{I}_{\mathrm{d} 1} \\
{[\mathrm{~mm}]}\end{array}$ & $\begin{array}{c}\mathrm{I}_{\mathrm{d} 2} \\
{[\mathrm{~mm}]}\end{array}$ & $\begin{array}{c}D_{\max 1} \\
{[\mathrm{~mm}]}\end{array}$ & $\begin{array}{l}D_{\max 2} \\
{[\mathrm{~mm}]}\end{array}$ & $\begin{array}{c}\varepsilon_{\max 1} \\
{[\%]}\end{array}$ & $\begin{array}{c}\varepsilon_{\max 2} \\
{[\%]}\end{array}$ & $\begin{array}{c}\text { Collapse } \\
\text { mode }\end{array}$ \\
\hline Tा1 & 595 & 1402 & 134.2 & 250 & 325 & 3.41 & 10.73 & 1.36 & 3.30 & $A-C$ \\
\hline$\pi 2$ & 1134 & 1367 & 130.8 & 250 & 325 & 2.27 & 10.03 & 0.91 & 3.09 & $A-C$ \\
\hline TT3 & 1434 & 1599 & 153.0 & 250 & 325 & 4.52 & 5.39 & 1.81 & 1.66 & $A-C$ \\
\hline TT4 & $-*$ & 1666 & 159.4 & 250 & 325 & 2.73 & 3.53 & 1.10 & 1.09 & $A-C$ \\
\hline TT5 & 402 & 1527 & 146.1 & 250 & 325 & 3.56 & 7.29 & 1.42 & 2.24 & $A-C$ \\
\hline Tा6 & 385 & 1376 & 131.7 & 250 & 250 & 2.93 & 2.61 & 1.17 & 1.04 & $A-C$ \\
\hline Tा7 & 618 & 1401 & 134.1 & 250 & 250 & 2.83 & 3.44 & 1.13 & 1.38 & $A-C$ \\
\hline $\begin{array}{l}T 18 * \\
*\end{array}$ & 430 & 1169 & 111.9 & 250 & 250 & 1.94 & 1.60 & 0.78 & 0.64 & $A-C$ \\
\hline 干T9 & 1140 & 1465 & 140.2 & 250 & 250 & 2.11 & 2.68 & 0.84 & 1.07 & $A-C$ \\
\hline Tा10 & 830 & 1381 & 132.2 & 250 & 250 & 1.95 & 2.97 & 0.78 & 1.19 & $A-C$ \\
\hline TT11 & 1012 & 1767 & 169.1 & 250 & 250 & 2.44 & 3.84 & 0.98 & 1.55 & $A-C$ \\
\hline TT12 & 1415 & 1650 & 157.9 & 250 & 250 & 2.33 & 2.91 & 0.93 & 1.64 & $A-C$ \\
\hline
\end{tabular}

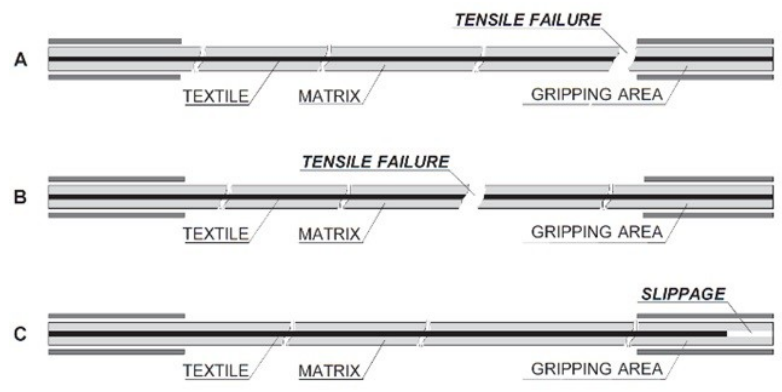

Fig. 9 Possible failure modes (A, B, C) of FRCM samples subjected to tensile tests [9]

The specimens (Fig. 8) revealed a first elastic phase, in which the stiffness is very high and difficult to measure accurately. Then, the first cracking of the mortar occurred, with a sudden drop of load followed by an important decrease of the stiffness. The load associated with the first crack showed a great variability; in fact, considering the reduced thickness of the samples, small defects may anticipate the cracking onset. However, the load increased again and the curves attain rapidly to the third phase, in which the slope agrees well with the stiffness of the yarns alone. The horizontal gap between the third phase and the yarns curve evidenced, in general, a non-negligible tension stiffening effect. This indicates that the yarns are, to some extent, still adherent to the mortar between the cracks. However, at the increasing of the load, a gradual reduction of the tension 
stiffening effect was observed in some samples (in particular TT3), indicating the progressive debonding of the yarns from the matrix.

Excluding TT8, where a premature collapse occurred, the average maximum tensile stress obtained (related to the dry fibers cross section) is of about $\sigma_{\max }=144.4 \mathrm{MPa}$ (CoV 9.3\%). The average distance among cracks is of about 135-140 mm, with a mean ultimate strain of about $1.19 \%$.

A combined collapse mode was, in general, detected (A-C, with reference to Fig. 9). In fact, once the mortar cracked in the vicinity of the clamping heads, the yarns-mortar slip mechanism was activated in the clamping area. This partial, progressive slippage, which reasonably was not identical in the yarns, induced an uneven stress distribution among them and tensile failure was observed only in some yarns.

The occurrence of the slippage is evident in the stress-strain curves plotted Fig. 10, which refer to the strains evaluated from the transducers with higher base length $\left(I_{d}=325 \mathrm{~mm}\right)$, in samples TT1 to TT5. The stiffness of the third branch, initially parallel to that of the yarns alone, rapidly decreases at the increase of the strain (exception only for sample TT4, as the slippage occurred out of the measurement base). A similar slippage phenomenon already emerged in some tensile tests performed by Gattesco and Boem [28], see also [30].

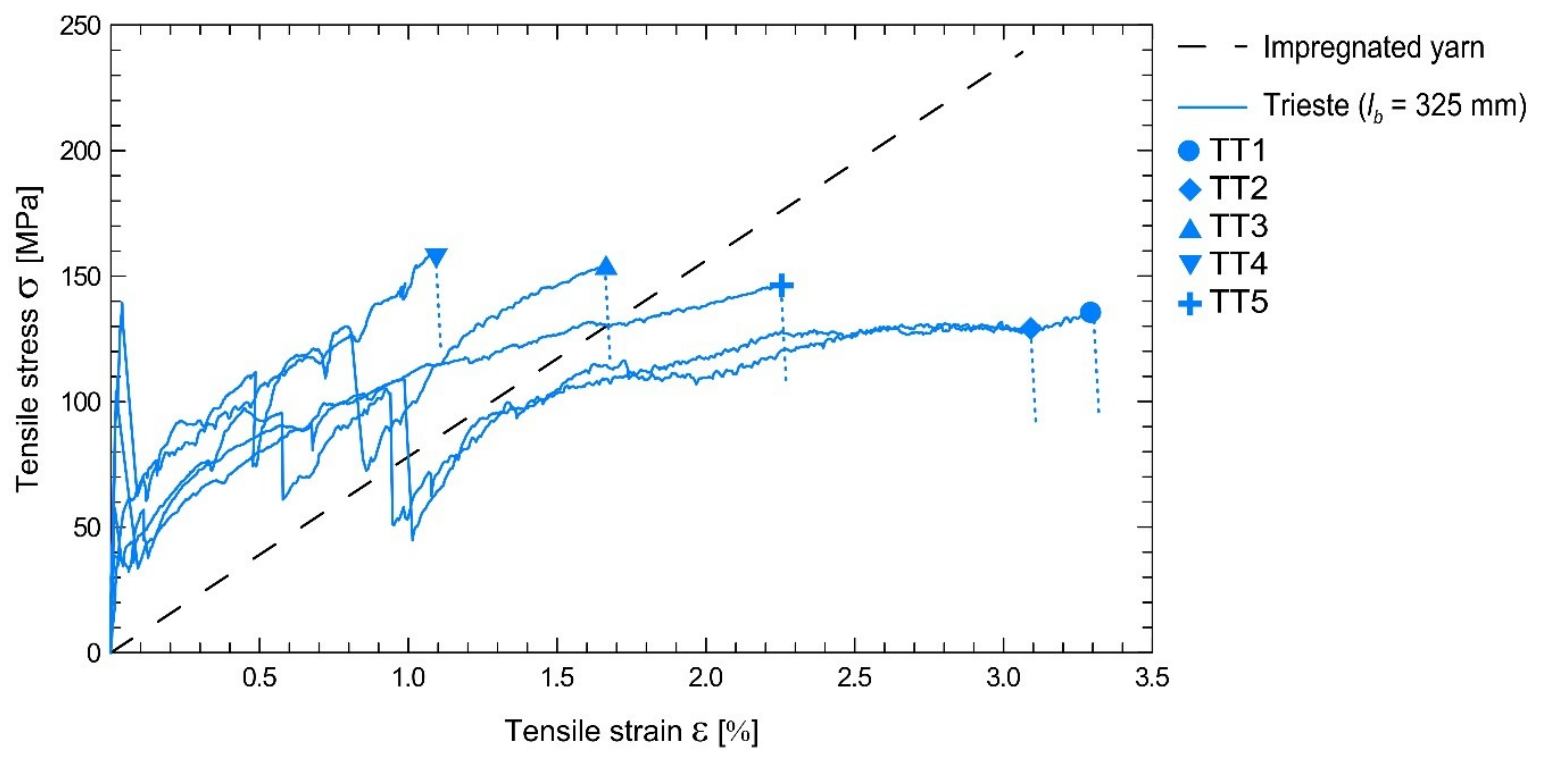

Fig. 10 Tensile behavior of Sisal-FRCM: stress-strain curves obtained by the Trieste laboratory (using transducers with a $325 \mathrm{~mm}$ base length).

Nevertheless, the curves in Fig. 8 result meaningful to describe the actual behavior of the composite: reasonably, in the absence of the yarns slippage from the mortar in correspondence of the clamping heads, the stress-strain curves would have shown the same trend. The third branch would have continued until reaching, at most, 239.7 MPa in case of perfectly uniform stress distribution among the yarns. However, this hypothesis is unrealistic: as emerged in bond tests ( $\underline{\text { see }}$ section 4), the reinforcement is able to attain to a lower stress value, associated to the progressive failure of the yarns (169.5 MPa).

The results presented show for the FRCM composite system with sisal yarns a moderate tensile strength and a ductile behavior, according to the tensile tests results on NFRCM made with sisal and flax textiles obtained by Olivito et al. [21]. However, the detected collapse mode leads to conclude that the clamping method adopted for high performance, "classic" FRCM, may be not properly adequate for lower mechanical performance composites such NFRCMs. Actually, to avoid the slippage of the yarns, it is not possible to increase significantly the compression of the clamping 
heads, as the crushing of the mortar would probably occur. Possible effective strategies can be, instead, the clamping of the yarns without the mortar matrix, e.g. by employing dry metallic tabs or the casting of holding heads made of high performance cement-based or resin.

\section{Sisal-NFRCM single-lap shear tests}

The bond behavior of Sisal-FRCM was evaluated through single-lap shear tests. The tests and corresponding findings are reported herein.

\subsection{Specimens}

The specimens for the single-lap shear tests (Fig. 11) consisted in a sisal-NFRCM layer applied on a masonry substrate. Five solid bricks $\left(55 \times 120 \times 250 \mathrm{~mm}^{3}\right)$ and four mortar joints (with $10 \mathrm{~mm}$ thickness) form the masonry prisms $\left(120 \times 250 \times 315 \mathrm{~mm}^{3}\right)$. The bricks have a normalized compressive strength of $15.7 \mathrm{MPa}$ [31]. The mechanical properties of the masonry mortar were determined

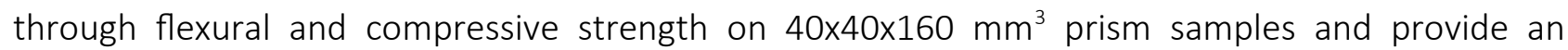
average flexural tensile strength of $2.1 \mathrm{MPa}$ and an average compressive strength of $5.4 \mathrm{MPa}$.

The Sisal-FRCM was applied on one prism face, at a distance of $30 \mathrm{~mm}$ from the upper face and 20 $\mathrm{mm}$ from both sides, following RILEM indications [32].The un-bonded yarns length is $400 \mathrm{~mm}$.

The geometry and arrangement of the yarns are the same of tensile tests samples (section 3): five impregnated yarns embedded in a NHL matrix and placed in the center of the mortar thickness (Fig. 12 ).

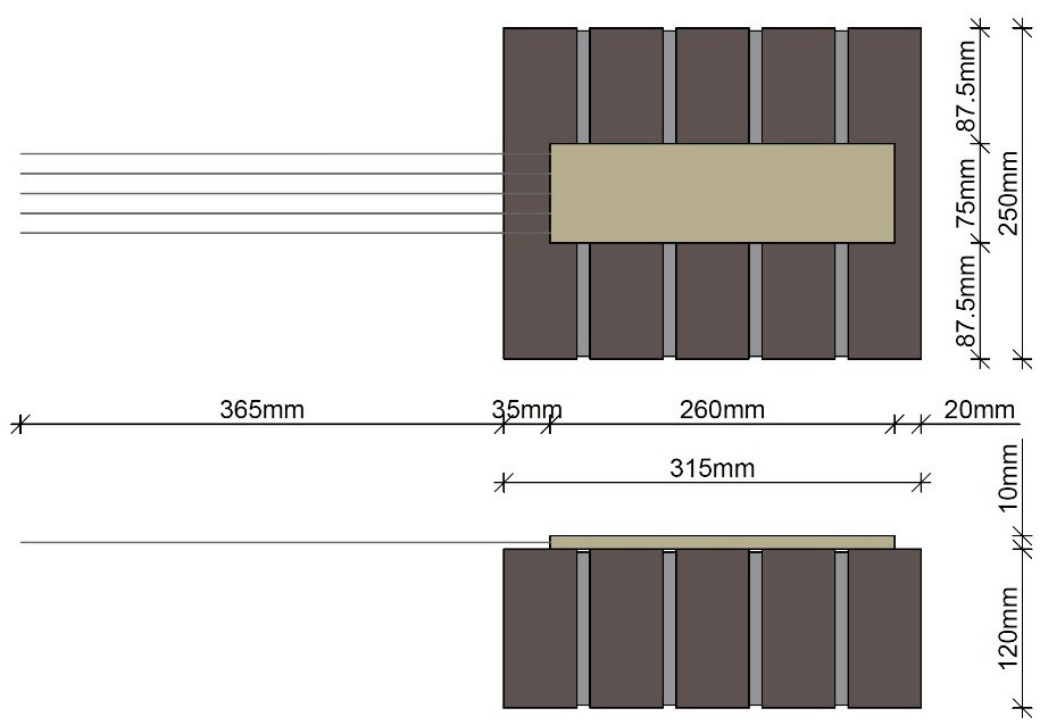

(a)

(b)

Fig. 11 Single-lap shear tests: specimen geometry: front (a) and lateral (b) views

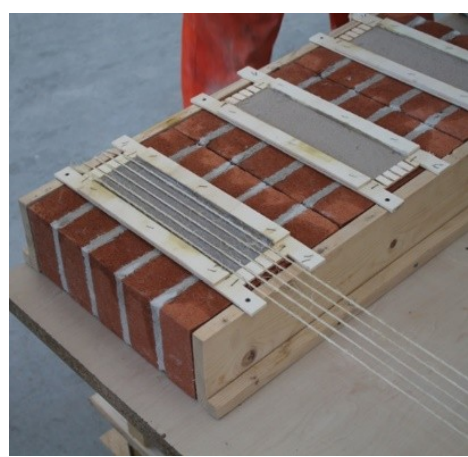

Fig. 12 Single-lap shear tests: specimen construction 


\subsection{Test set-up and procedure}

In the University IUAV of Venice laboratory, the tests were carried out with the same testing machine described for tensile tests, under displacement control (Fig. 13 a). A metallic device, shaped as a seat, was used to support the masonry prisms [33]. The device was set so to maintain the yarns in the vertical direction and ensure the vertical alignment of the load along the specimens, taking care to avoid parasitic forces, perpendicular to the masonry surface, which could anticipate the sample failure (Fig. 13 e-f). Two digital transducers were positioned along the specimens to measure the relative displacement between the masonry substrate and the yarns (Fig. 13 b).

The test apparatus of the University of Trieste laboratory (Fig. 13 c-d) was for the most the same of that employed for the tensile tests, but replacing the upper clamps with a metallic device similar to that already described for the setup of the University IUAV of Venice. Two potentiometer transducers measured the displacement between the yarns and the masonry prism. Two adjunctive potentiometer transducers monitored the displacement between the mortar layer and the masonry. However, these potentiometers revealed negligible displacements $(<0.1 \mathrm{~mm})$.

In both laboratories, the yarns extremities were clamped through two metallic plates, coupled with bolts, to avoid the yarns slippage. At the beginning of the tests, the length of unbounded yarns included in the measurement base was $I_{d}=160 \mathrm{~mm}$. A load rate of about $0.6 \mathrm{~mm} / \mathrm{min}$ (acquisition frequency $5 \mathrm{~Hz}$ ) was considered.

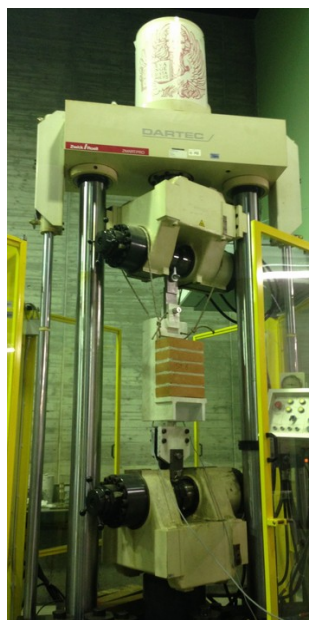

(a)

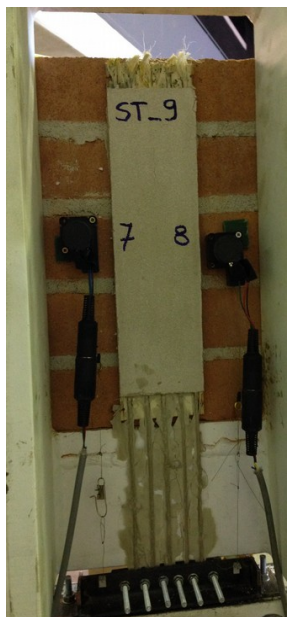

(b)

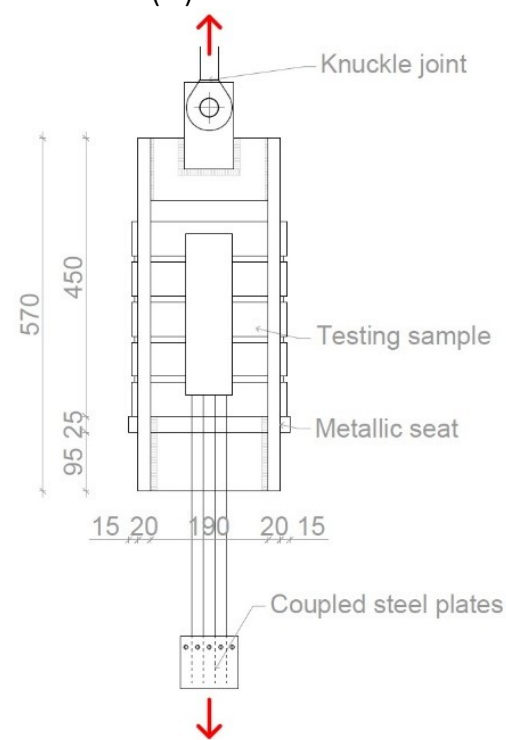

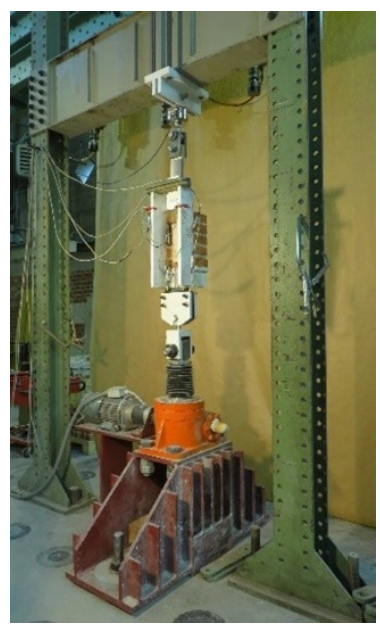

(c)

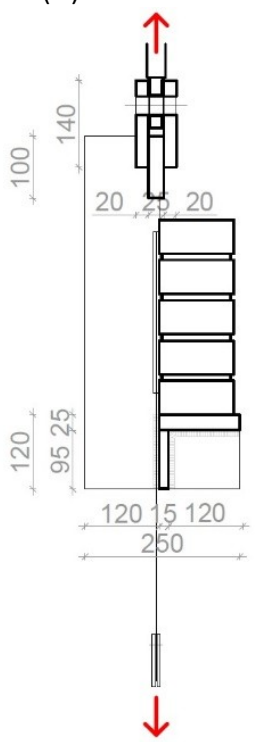

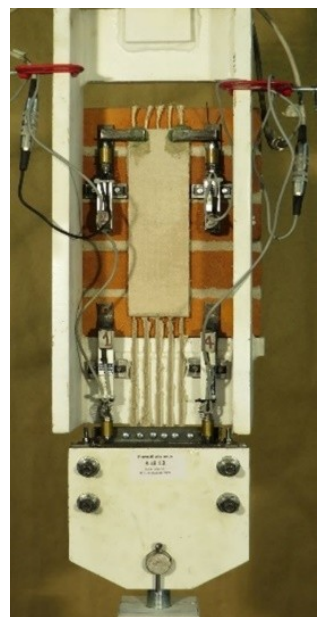

(d) 
(e)

(f)

Fig. 13 Single-lap shear test: University IUAV of Venice test set-up (a) and transducers (b); University of Trieste test set-up (c) and transducers (d); frontal view (e) and lateral section (f) of the test apparatus

\subsection{Results and discussions}

Fig. 14 shows the samples after the tests. The samples tested at the University of Trieste were named ST1 up to ST6 and University IUAV of Venice ones are ST7 up to ST12. Actually, samples ST7 and ST8 were not considered, due to a premature damage emerged during testing, related to a sample defect associated to the construction process.

The stress-strain curves obtained from the single-lap shear tests are plotted in Fig. 15 (the stresses are related to the global fibers cross-section $\left(10.45 \mathrm{~mm}^{2}\right)$, the strains are referred to a base length $l_{d}=160 \mathrm{~mm}$ ). The results of each laboratory are coherent and the Trieste and Venice curves are quite comparable.

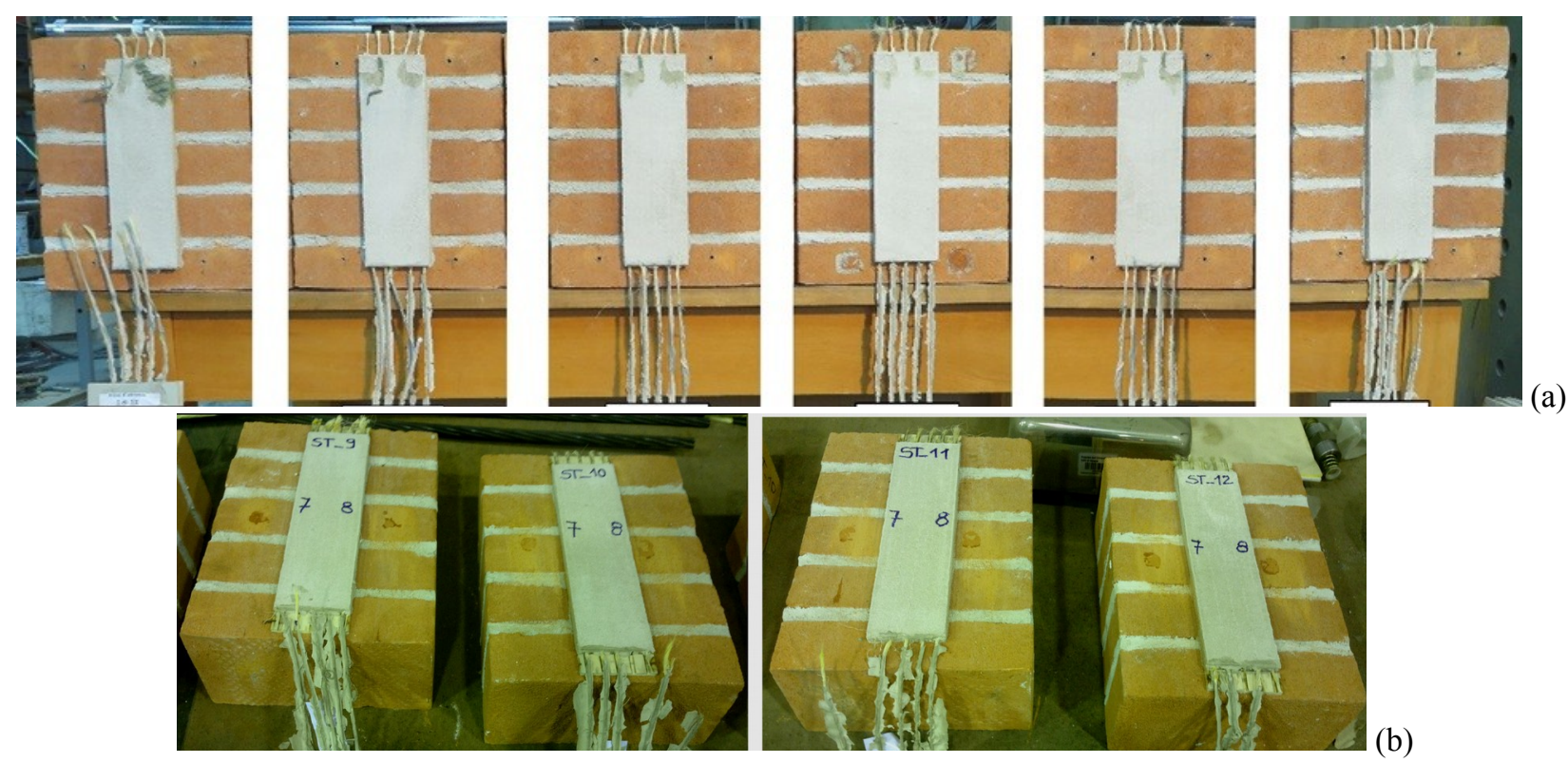

Fig. 14 Sisal-FRCM samples after the shear bond tests performed in Trieste ST1-ST6 (a) and in Venice ST9-ST12 (b)

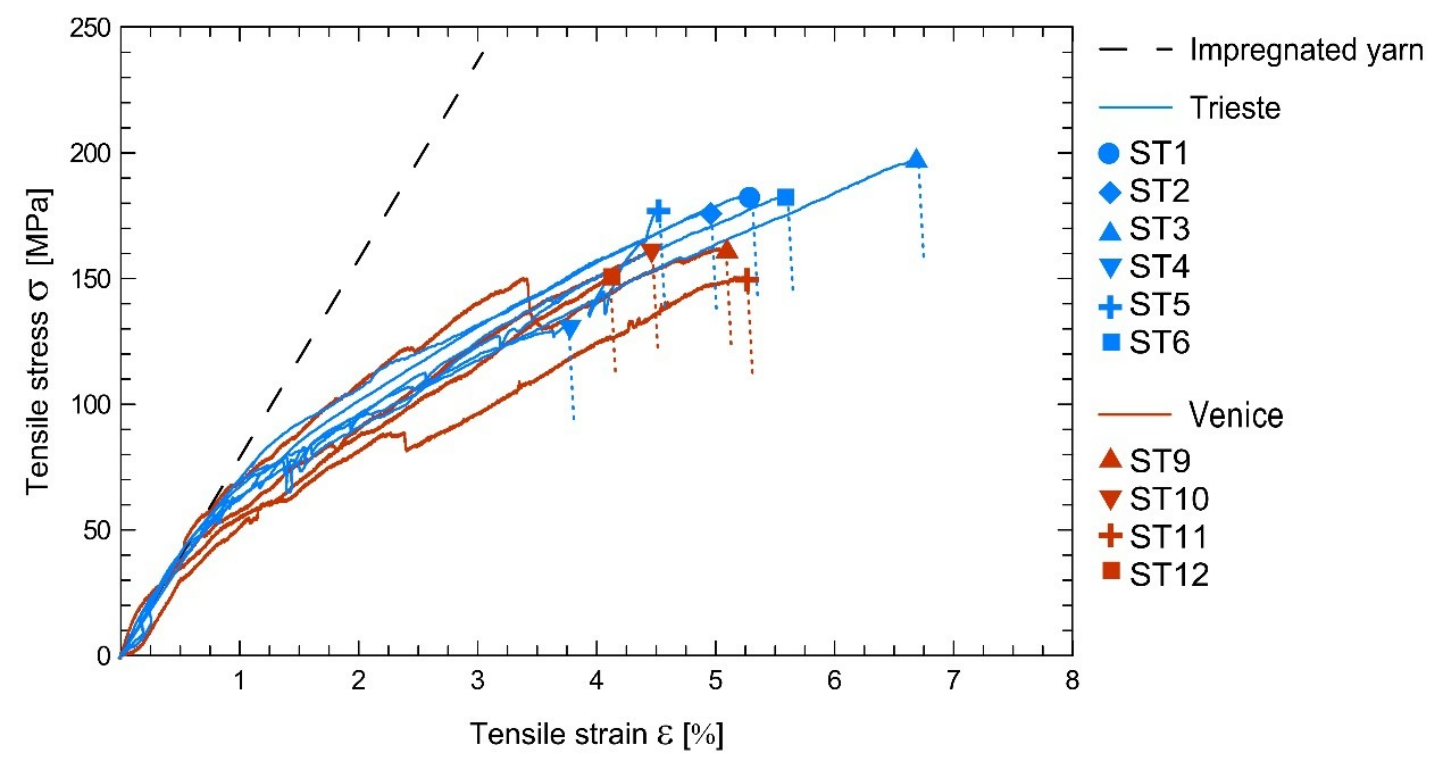


Fig. 15 Single-lap shear tests of Sisal-FRCM: stress-strain curves obtained by the Trieste and Venice laboratories.

The main results are summarized in the Tab. 2 , that reports the peak load $\left(F_{\max }\right)$, the average displacement measured by the transducers in correspondence to the peak load $\left(D_{\max }\right)$, the average strain at peak load $\left(\varepsilon_{\max }\right)$ obtained by dividing $D_{\max }$ for $I_{d}$, the peak load per unit of width $\left(F_{\max } / w\right)$, where $w=75 \mathrm{~mm}$; the peak stress in the yarns $\left(\sigma_{\max }=F_{\max } / A_{f}\right)$, where $A_{f}$ is the fibers cross section $\left(2.09 \mathrm{~mm}^{2} \times 5=10.45 \mathrm{~mm}^{2}\right)$ and the the failure mode, in accordance with RILEM protocol (Fig. 16).

It is evidenced that the monitored yarns-mortar displacements may be due, in general, both to the elongation of the yarns and to the relative yarns-mortar slippage. Actually, at the beginning of the test, there was the perfect adhesion between the yarns and the mortar, thus the displacement was initially determined only by the elongation of the unbounded yarns portion $\left(I_{d}=160 \mathrm{~mm}\right)$, as evidenced in Fig. 15. The progressive deviation of the ST curves from that of the yarns, which started at about $60 \mathrm{MPa}$, revealed the progressive slip and partial debonding of the yarns from the mortar matrix, due to the failure of the chemical adhesion. However, no evident yarns slippage emerged in correspondence of the upper edge of the mortar layer.

Tab. 2 Single-lap shear tests results

\begin{tabular}{ccccccc}
\hline Sample & $\begin{array}{c}\boldsymbol{F}_{\max } \\
{[\mathrm{N}]}\end{array}$ & $\begin{array}{c}D_{\max } \\
{[\mathrm{mm}]}\end{array}$ & $\begin{array}{c}\boldsymbol{\varepsilon}_{\max } \\
{[\%]}\end{array}$ & $\begin{array}{c}\boldsymbol{F}_{\max } / \boldsymbol{w} \\
{[\mathrm{N} / \mathrm{mm}]}\end{array}$ & $\begin{array}{c}\boldsymbol{\sigma}_{\max } \\
{\left[\mathrm{N} / \mathrm{mm}^{2}\right]}\end{array}$ & $\begin{array}{c}\text { Failure } \\
\text { mode }\end{array}$ \\
\hline ST1 & 1912 & 10.50 & 5.25 & 25.84 & 183.0 & E2 \\
\hline ST2 & 1850 & 9.84 & 4.92 & 25.00 & 177.0 & E2 \\
\hline ST3 & 2062 & 13.38 & 6.69 & 27.86 & 197.3 & E2 \\
\hline ST4 & 1391 & 6.74 & 3.37 & 18.80 & 133.1 & E2 \\
\hline ST5 & 1858 & 9.01 & 4.50 & 25.11 & 177.8 & E2 \\
\hline ST6 & 1911 & 11.22 & 5.61 & 25.82 & 182.9 & E2 \\
\hline ST9 & 1693 & 9.86 & 4.93 & 22.87 & 162.0 & E1 \\
\hline ST10 & 1751 & 14.10 & 7.05 & 23.67 & 167.6 & E2 \\
\hline ST11 & 1573 & 10.32 & 5.16 & 21.26 & 150.5 & E2 \\
\hline ST12 & 1715 & 13.42 & 6.71 & 23.17 & 164.1 & E2 \\
\hline
\end{tabular}

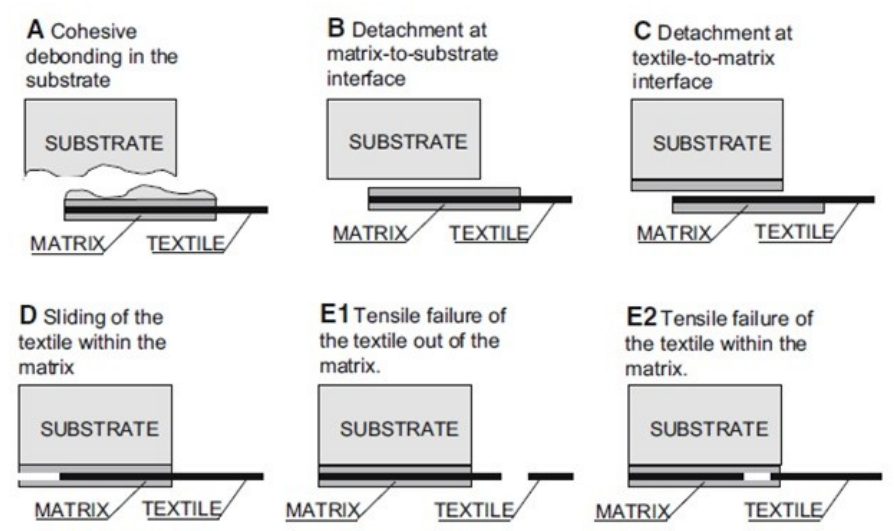

Fig. 16 FRCM failure modes (A, B, C, D, E1, E2) for single-lap shear tests [33]

In general, the samples demonstrated a similar behavior, with the fibers rupture within the bond area, corresponding with the failure mode E2 (Fig. 16). Exception for the sample ST9, whose behavior corresponds to the failure mode E1 (fibers rupture out of the matrix). A bond length of $260 \mathrm{~mm}$ resulted thus adequate for Sisal-NFRCM to attain to the yarns rupture, avoiding premature 
failures due to debonding or sliding. The average maximum tensile stress obtained (related to the dry fibers cross--section) is about $\sigma_{\max }=169.5 \mathrm{MPa}$ (CoV 11\%). These value resulted about $29 \%$ lower than that obtained from tensile tests on a single impregnated yarn (239.7 $\mathrm{MPa}$ ) and is attributable to an uneven distribution of the stresses among the yarns.-

It is also observed that, in general, the ST tests provided resistance values higher than those of the TT tests, as no premature slippage occurred at the yarns clamping.

No slips or detachments were observed at the masonry-mortar interface (failure modes A or B in Fig. 16), thus it was not possible to quantify the masonry-mortar bond strength. However, for the considered sisal-NFRCM, it is reasonable to consider unrealistic these kinds of failure, even for lower bond lengths, due to the reduced tensile load and the activation of the yarns slippage from the mortar matrix.

\section{Main remarks and conclusions}

A first approach to the mechanical characterization of a FRCM solution made of natural fibers (NFRCM) was performed. In particular, the investigated reinforcement consisted of sisal fibers yarns impregnated with a water-based resin and embedded in an inorganic matrix based on natural lime. Following the RILEM group recommendations for classic FRCMs, tensile tests (TT) and single-lap shear tests (ST) on sisal-NFRCM samples were carried out. The experimental tests were performed in two laboratories at the University IUAV of Venice and the University of Trieste. In general, the results of the two laboratories resulted in good agreement proving the repeatability of the tests.

For the impregnated yarns, the mechanical characterization of the NFRCM coupons evidenced an elastic-brittle behavior (axial stiffness of about $16413 \mathrm{~N}$ ) with a higher tensile strength (239.7 MPa) with respect to dry fibers yarns (209.1 MPa), due to a more uniform distribution of the stresses among the fibers.

In TT tests, the stress-strain curves revealed an initial stiff un-cracked phase, followed by a sudden drop of resistance as the mortar cracked. Then, the stress progressively increased and the slope of the curves became similar to the stiffness of the dry sisal yarns. A non-negligible tension stiffening effect emerged, which however tended gradually to reduce at the increasing of the strain. The average distance between cracks resulted in about 135-140 mm.

The premature failure of TT samples allowed to ascertain that the clamping of the yarns without involving the mortar matrix should be preferred for NFRCM specimens, where the bond between the reinforcement and the matrix is significantly weaker than in classical FRCMs. Differently, once the mortar cracked in the vicinity of the clamping heads, the progressive yarns-mortar slip phenomenon occurred in the gripping area.

However, TT tests resulted meaningful for the sisal-NFRCM characterization: the maximum tensile stress reached fabout $144.4 \mathrm{MPa}$ (in correspondence to a mean ultimate strain of $1.19 \%$ ), resulted only a little lower than that emerged from ST tests, where premature failure did not occur.

In ST tests, a progressive, partial debonding of the yarns from the mortar matrix emerged, however the tensile failure of the yarns was always attained and no slip was observed at the masonry-mortar interface: the bond length of $260 \mathrm{~mm}$ resulted thus adequate for Sisal-NFRCM to avoid failure by debonding or sliding. The maximum tensile strength obtained from ST tests (169.5 MPa) resulted about 29\% lower than that measured on impregnated yarns alone, evidencing an uneven load distribution among the yarns, due to a non-uniform loss of the yarns-mortar chemical adhesion.

Further experiments; considering shorter bond lengths should be carried out to assess the minimum bond length value that permits to reach the yarns tensile failure. However, reasonably, the detachment of the mortar from the masonry substrate is not expected, as the yarns slippage occurs. 
The first results obtained for sisal-FRCM samples reported in this paper represent an initial and important step into the investigation of the NFRCM mechanical behavior and to set mechanical tests for the material characterization and design. Furthermore, the experimental results achieved within this work are also useful for analytical and numerical simulations.

\section{Acknowledgments}

The authors acknowledge Fibre Net SpA (Pavia di Udine, Italy), the Construction science laboratory of the University IUAV of Venice (Labsco) and the Laboratory of Testing Materials of the University of Trieste for the support given at these experimental tests. This work was partly financed by the research project PRIN 2015 (under grant 2015JW9NJT_014, project "Advanced mechanical modeling of new materials and structures for the solution of 2020 Horizon challenges") and FEDER funds through the Competitively Factors Operational Programme - COMPETE and by national funds through FCT - Foundation for Science and Technology within the scope of projects POCl-01-0145FEDE-007633.

\section{References}

[1] AC434. Acceptance Criteria for Masonry and Concrete Strengthening Using Fabric Reinforced Cementitious Matrix (FRCM) Composite Systems. International Code Council standard, 2016.

[2] $\mathrm{ACl}$ 549.4R-13. Guide to Design and Construction of Externally Bonded Fabric-Reinforced Cementitious Matrix (FRCM) Systems for Repair and Strengthening Concrete and Masonry Structures. American Concrete Institute. Farmington Hills, MI, USA, 2013.

[3] S. De Santis, F.G. Carozzi, G. de Felice, C. Poggi, Test Methods for Textile Reinforced Mortar Systems, Composites Part B: Engineering. 127 (2017) 121-132.

[4] L. Ascione, G. De Felice, S. De Santis, A Qualification Method for Externally Bonded Fibre Reinforced Cementitious Matrix (FRCM) Strengthening Systems, Composites Part B: Engineering 78 (2015) 497-506.

[5] G.P. Lignola, C. Caggegi, F. Ceroni, S. De Santis, P. Krajewski, P.B. Lourenço, M. Morganti, et al., Performance Assessment of Basalt FRCM for Retrofit Applications on Masonry, Composites Part B: Engineering 128 (2017) 1-18.

[6] F.G. Carozzi, A. Bellini, T. D'Antino, G. de Felice, F. Focacci, Ł. Hojdys, L. Laghi, et al., Experimental Investigation of Tensile and Bond Properties of Carbon-FRCM Composites for Strengthening Masonry Elements, Composites Part B: Engineering 128 (2017) 100-119.

[7] M. Leone, M.A. Aiello, A. Balsamo, F.G. Carozzi, F. Ceroni, M. Corradi, M. Gams, et al., Glass Fabric Reinforced Cementitious Matrix: Tensile Properties and Bond Performance on Masonry Substrate, Composites Part B: Engineering 127 (2017) 196-214.

[8] C. Caggegi, F.G. Carozzi, S. De Santis, F. Fabbrocino, F. Focacci, Ł. Hojdys, E. Lanoye, L. Zuccarino, Experimental Analysis on Tensile and Bond Properties of PBO and Aramid Fabric Reinforced Cementitious Matrix for Strengthening Masonry Structures, Composites Part B: Engineering 127 (2017) 175-195.

[9] S. De Santis, F. Ceroni, G. de Felice, M. Fagone, B. Ghiassi, A. Kwiecień, G.P. Lignola, M. Morganti, M. Santandrea, M.R. Valluzzi, A. Viskovic A, Round Robin Test on tensile and bond behaviour of Steel Reinforced Grout systems, Composites Part B: Engineering 127 (2017) 100120. 
[10] S.F. Santos, G.H.D. Tonoli, J.E.B. Mejia, J. Fiorelli, H. Savastano Jr., Non-Conventional CementBased Composites Reinforced with Vegetable Fibers: A Review of Strategies to Improve Durability, Materiales De Construccion, 65 (2015) 317:e041.

[11] T. Gurunathan, S. Mohanty, S.K.A. Nayak, Review of the Recent Developments in Biocomposites Based on Natural Fibres and their Application Perspectives, Composites Part A: Applied Science and Manufacturing 77 (2015) 1-25.

[12] M.E.A. Fidelis, F. De Andrade Silva, R.D.T. Filho, The Influence of Fiber Treatment on the Mechanical Behavior of Jute Textile Reinforced Concrete, Key Engineering Materials 600 (2014) 469-474.

[13] G. Cicala, G. Cristaldi, G. Recca, A. Latteri. Composites Based on Natural Fiber Fabricsm in: Polona Dobnik Dubrovski ed., Woven Fabric Engineering, InTech, 2010.

[14] A. Ticoalu, T. Aravinthan, F. Cardona, A Review of Current Development in Natural Fiber Composites for Structural and Infrastructure Applications, Southern Region Engineering Conference, 10-12 November, 2010, Toowoomba, Australia.

[15] K. Begum, M.A. Islam, Natural Fiber as a substitute to Synthetic Fiber in Polymer Composites: A Review, Research Journal of Engineering Sciences 2 (2013) 3:46-53.

[16] L.C. Roma Jr, L.S. Martello, H. Savastano Jr, Evaluation of Mechanical, Physical and Thermal Performance of Cement-Based Tiles Reinforced with Vegetable Fibers, Construction and Building Materials 22 (2008) 4:668-674.

[17] M. Ardanuy, J. Claramunt, J.A. García-Hortal, M. Barra, Fiber-Matrix Interactions in Cement Mortar Composites Reinforced with Cellulosic Fibers, Cellulose 28 (2011) 2:281-289.

[18] R.D. Toledo Filho, K. Scrivener, G.L. England, K. Ghavami, Durability of Alkali-Sensitive Sisal and Coconut Fibres in Cement Mortar Composites, Cement and Concrete Composites 22 (2000) 2:127-143.

[19] P.R.L. Lima, R.D. Toledo Filho, Use of metakaolin to improve the durability of sisal fiber-cement based composites, Ambiente Construído 8 (2008) 4:7-19.

[20] L. Ferrara, A.R. Ferreira, V. Krelani, F. Silva, R.D. Toledo Filho, Effect of natural fibres on the self healing capacity of high performance fibre reinforced cementitious composites, in: Proceedings of shcc rilem 3rdInternational RILEM Conference on Strain Hardening Cementitious Composites, 2014,_Dordrecht, the Netherlands.

[21] R.S. Olivito, O.A. Cevallos, A. Carrozzini, Development of Durable Cementitious Composites using Sisal and Flax Fabrics for Reinforcement of Masonry Structures, Materials and Design 57 (2014) 258-268.

[22] C.B. De Carvalho Bello, A. Cecchi, Experiments on natural fibers: durability and mechanical properties, Advances in Materials \& Processing Technologies journal 3 (2017) 4:632-639.

[23] EN ISO 1889:2009, Reinforcement yarns - Determination of linear density, 2009, CEN, Brussels (BE).

[24] K.L. Pickering, M.G. Aruan Efendy, T.M. Le. Review of recent developments in natural fibre composites and their mechanical performance, Composites Part A: Applied Science and Manufacturing 83 (2016) 98-112. 
[25] CNR-DT 200 R1/2013, Guide for the design and construction of externally bonded FRP systems for strengthening existing - Materials, RC and PC structures, masonry structures, CNR - Advisory Committee on Technical Recommendations for Construction, 2013.

[26] EN 1998-1:2004, Eurocode 8: Design of structures for earthquake resistance - Part 1: General rules, seismic actions and rules for buildings, 2004, CEN, Brussels (BE).

[27] EN196-1:2016, Methods of testing cement - Part 1: Determination of strength. 2006, CEN, Brussels (BE).

[28] N. Gattesco, I. Boem, Characterization Tests of GFRM Coating as a Strengthening Technique for Masonry Buildings, Composite Structures 165 (2017) 209-222.

[29] G. Tumilan, A. De Luca, The Second Generation of Externally-Bonded Composite Systems for Strengthening of Concrete and Masonry Structures, Structure Magazine Setp.29 (2014) 22-24.

[30] D. Arboleda, F.G. Carozzi, F.G., A. Nanni, C. Poggi, Testing procedures for the uniaxial tensile characterization of fabric-reinforced cementitious matrix composites, Journal of Composites for Construction, 20(3), June 2016, https://doi.org/10.1061/(ASCE)CC.1943-5614.0000626.

[31] EN772-1:2011+A1:2015, Methods of test for masonry units. Part 1: Determination of compressive strength, 2015, CEN, Brussels (BE).

[32] G. De Felice, M.A. Aiello, C. Caggegi et al., Recommendation of RILEM Technical Committee 250-CSM: Test method for Textile Reinforced Mortar to substrate bond characterization, Mater Struct 51 (2018) 95.

[33] Leone, M., M. A. Aiello, A. Balsamo, F. G. Carozzi, F. Ceroni, M. Corradi, M. Gams, et al. 2017. "Glass Fabric Reinforced Cementitious Matrix: Tensile Properties and Bond Performance on Masonry Substrate." Composites Part B: Engineering 127: 196-214. 